\title{
PERANCANGAN DAN IMPLEMENTASI DIRECTIONAL FEATURE EXTRACTION DAN SUPPORT VECTOR MACHINES UNTUK MENERJEMAHKAN KATA DENGAN PENGENALAN HURUF HIRAGANA DALAM BAHASA JEPANG KE BAHASA INDONESIA BERBASIS ANDROID
}

\author{
Fardilla Zardi Putri ${ }^{1}$, Budhi Irawan ${ }^{2}$, Umar Ali Ahmad ${ }^{3}$ \\ ${ }^{1,2,3}$ Fakultas Teknik Elektro, Universitas Telkom \\ 1' fardillaputri@gmail.com, ${ }^{2}$ budhiirawan@telkomuniversity.ac.id, ${ }^{3}$ umar@ $@$ telkomuniversity.ac.id
}

\begin{abstract}
Abstrak
Pada era global ini menguasai bahasa selain bahasa Indonesia merupakan salah satu kebutuhan penting yang harus dimiliki setiap orang. Banyak orang berkunjung ke negara lain untuk melakukan banyak kegiatan seperti bekerja, belajar, bahkan berlibur. Salah satu negara yang banyak dikunjungi adalah negara Jepang. Negara Jepang memiliki bentuk huruf yang berbeda dengan huruf latin pada umumnya. Untuk mempelajari bahasa Jepang tersebut dibutuhkan pemahaman dengan huruf-hurufnya. Seiring dengan berkembangnya teknologi, pengenalan karakter atau sering Optical Character Recognition (OCR) merupakan salah satu aplikasi teknologi pada bidang pengenalan karakter atau pola dan kecerdasan buatan sebagai mesin pembaca. Pada penelitian ini, akan dirancang sebuah aplikasi penerjemah kata dalam bahasa Jepang berbasis Android dengan memanfaatkan prinsip dasar OCR dengan menggunakan metode Directional Feature Extraction dan Support Vector Machine. Pengujian yang dilakukan memberikan hasil terbaik pada nilai akurasi yang dicapai dengan menggunakan metode Directional Feature Extraction dan Support Vector Machine adalah 85,71\%. Pada penelitian ini, menggunakan 104 data latih. Hasil pengujian Beta atas empat poin, yaitu tampilan aplikasi, waktu respons sistem, ketepatan penerjemahan, dan manfaat aplikasi menunjukkan aplikasi dapat diklasifikasikan baik.
\end{abstract}

Kata Kunci: Optical Character Recognition, Directional Feature Extraction, Support Vector Machine, Android

\begin{abstract}
In this global era mastering language besides bahasa Indonesia is one of the important needs that must be owned by everyone. Many people visit other countries to do a lot of activities such as work, study and even for a holiday. One of the most countries visited is Japan. Japanese state has a different shape with the Latin alphabet in general. To learn the Japanese language requires an understanding with the letters. Along with the development of technology, character recognition or often called Optical Character Recognition (OCR) is one application of technology in the field of character or pattern recognition and artificial intelligence as reading machines. In this research, we will design an application in Japanese language word translator based Android by utilizing basic principles of OCR using the Directional Feature Extraction and Support Vector Machine. Tests was done to give the best results on the value of accuracy is achieved by using Directional Feature Extraction and Support Vector Machine is $85.71 \%$. This study is using 104 training data. Beta Testing result on four points, namely the display application, system response time, accuracy of translation, and the benefits of the application shows that the application can be classified as good.
\end{abstract}

Keyword: Optical Character Recognition, Directional Feature Extraction, Support Vector Machine, Android

\section{Pendahuluan}

Pada era global ini menguasai bahasa selain Bahasa Indonesia merupakan salah satu kebutuhan penting yang harus dimiliki setiap orang. Banyak orang berkunjung ke negara lain untuk melakukan banyak kegiatan seperti bekerja, belajar bahkan untuk liburan. Salah satu negara yang banyak dikunjungi adalah negara Jepang. Saat mengunjungi negara tersebut para pengunjung akan kesulitan membaca dan mengartikan setiap kata dalam bahasa Jepang. Saat ini, android merupakan salah satu teknologi yang sangat berkembang dan banyak diminati berbagai kalangan. Android merupakan Operating System yang banyak digunakan oleh pengguna mobile phone. Sifatnya yang open source memungkinkan pengguna menambahkan aplikasi sesuai kebutuhan. Mobile phone yang berbasis android tersebut juga sering dibawa kemana-mana oleh penggunanya. Seiring dengan berkembangnya teknologi, pengenalan karakter dapat dibantu dengan sebuah alat seperti scanner. Optical Character Recognition (OCR) merupakan salah satu aplikasi teknologi pada bidang pengenalan karakter atau pola dan kecerdasan buatan sebagai mesin pembaca.

Pada penelitian ini akan dirancang sebuah aplikasi penerjemah bahasa Jepang berbasis android. Dengan menggunakan prinsip Optical Character Recognition (OCR) untuk mengenali huruf dalam 
bahasa Jepang yang tertangkap oleh kamera handphone. Citra masukan diolah dan diekstraksi untuk mendapatkan ciri dari huruf dalam bahasa Jepang menggunakan metode Directional Feature Extraction. Sedangkan metode Support Vector Machine akan digunakan pada tahap pengklasifikasian. Oleh karena itu, dengan adanya aplikasi ini diharapkan dapat membantu para pengunjung negara Jepang terutama pengunjung dari Indonesia dalam menerjemahkan setiap kata dalam Bahasa Jepang.

\section{Android}

Android adalah suatu sistem operasi yang didesain sebagai platform open source untuk perangkat mobile berbasis linux yang mencakup sistem operasi, middleware, dan aplikasi. Android menyediakan platform yang terbuka bagi para pengembang untuk menciptakan aplikasi mereka. Android menyediakan semua tools dan framework untuk mengembangkan aplikasi dengan mudah dan cepat. Dengan adanya Android SDK (Software Developement Kit) pengembang aplikasi dapat memulai pembuatan aplikasi pada platform android menggunakan bahasa pemrograman Java.

\section{Hiragana Jepang}

Dalam Bahasa Jepang terdapat tiga jenis aksara yaitu Hiragana, Katakana dan Kanji. Huruf Hiragana dan Katakana dibuat oleh orang Jepang sendiri sedangkan huruf Kanji berasal dari Cina. Huruf Hiragana digunakan untuk menuliskan kata asli dari bahasa Jepang (bukan kata serapan). Huruf Hiragana didasarkan pada lima bunyi vokal, yaitu a, i, u, e, dan o. Vokal ini dapat digunakan sendiri ataupun digunakan bersama sebuah konsonan (misalnya m dan a menjadi ma) atau konsonan ditambah semivokal y (misalnya m, y, dan a menjadi mya).

\begin{tabular}{|c|c|c|c|c|c|c|c|c|c|c|c|c|c|c|c|}
\hline $\begin{array}{c}\bar{\hbar} \\
a\end{array}$ & $\begin{array}{l}\text { מ } \\
\text { ka }\end{array}$ & $\begin{array}{l}\text { さ } \\
\text { sa }\end{array}$ & "た & な & 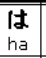 & \begin{tabular}{c|} 
末 \\
ma
\end{tabular} & や & $\begin{array}{l}5 \\
\mathrm{ra}\end{array}$ & 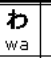 & & ss & 己 & $\begin{array}{l}\text { だ } \\
\text { da }\end{array}$ & ば & $\begin{array}{l}\text { ば } \\
\text { pa }\end{array}$ \\
\hline 6 & $\begin{array}{l}\text { き } \\
\mathrm{ki}\end{array}$ & Lhi & & & Zs & $\begin{array}{l}\text { み } \\
\mathrm{mi}\end{array}$ & & b & & & ₹ & $\underset{\mathrm{ji}}{\mathrm{L}}$ & $\begin{array}{l}5 ゙ \\
\mathrm{ji}\end{array}$ & $\begin{array}{l}ひ ゚ \\
\text { bi }\end{array}$ & $\begin{array}{l}\text { ひi } \\
\text { pi }\end{array}$ \\
\hline$j$ & ku & $\begin{array}{l}\text { す } \\
\text { su }\end{array}$ & 7 & & 31 & $\begin{array}{c}\text { む } \\
\mathrm{mu}\end{array}$ & & \begin{tabular}{l|} 
る \\
$\mathrm{ru}$
\end{tabular} & & & $\begin{array}{l}< \\
\text { gu }\end{array}$ & d* & $\begin{array}{l}3 \\
z u\end{array}$ & & 30 \\
\hline $\bar{\lambda}$ & $\begin{array}{l}\text { け } \\
\mathrm{ke}\end{array}$ & $\begin{array}{l}\text { せ } \\
\text { se }\end{array}$ & $\begin{array}{l}\tau \\
\text { te }\end{array}$ & $h$ & $\hat{0}$ & $\begin{array}{l}\phi \\
\text { me }\end{array}$ & & れ & & & $\begin{array}{l}\text { If } \\
\text { ge }\end{array}$ & ザ & c & & 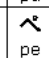 \\
\hline お & $\Sigma_{\text {ko }}$ & $\begin{array}{l}z \\
\text { so }\end{array}$ & 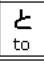 & & & $\begin{array}{c}\text { も } \\
\text { mo }\end{array}$ & & 3 & を & $\begin{array}{l}h \\
\mathrm{n}\end{array}$ & g̈ & $\begin{array}{l}Z \\
z 0 \\
z 0\end{array}$ & \begin{tabular}{l|l} 
ど & 1 \\
do
\end{tabular} & \begin{tabular}{|l|}
$£$ \\
bo \\
\end{tabular} & 17 \\
\hline & $\begin{array}{l}C+1 \\
\text { sha }\end{array}$ & & & & & & & $\begin{array}{l}\text { ひゃ } \\
\text { rya }\end{array}$ & & & $\mathrm{ja}$ & $\begin{array}{c}5{ }^{\circ} \\
\end{array}$ & bya & & \\
\hline きゅ & $\begin{array}{l}\text { LA } \\
\text { shu }\end{array}$ & & $\begin{array}{l}5 \text { क } \\
\text { chu }\end{array}$ & & & & & $\begin{array}{l}\text { ひゅ } \\
\text { ryu }\end{array}$ & & & $\mathcal{C}_{\mathrm{ju}}$ & $\begin{array}{c}5 \% \\
\mathrm{ju}\end{array}$ & $\begin{array}{l}\text { びゅ } \\
\text { byu }\end{array}$ & & \\
\hline & & & 5 & & $\begin{array}{l}\text { Ud } \\
\text { hyo }\end{array}$ & 2 & $\begin{array}{l}\text { みよ } \\
\text { myo }\end{array}$ & $\begin{array}{l}\text { りよ } \\
\text { ryo }\end{array}$ & $\begin{array}{l}\text { हैよ } \\
\text { gyo }\end{array}$ & & $\begin{array}{c}\mathrm{C}_{\mathrm{j}} \\
\text { jo }\end{array}$ & $\begin{array}{c}5 よ \\
\text { jo }\end{array}$ & $\begin{array}{l}\text { びよ } \\
\text { byo }\end{array}$ & & ชீ \\
\hline
\end{tabular}

Gambar 1. Huruf Hiragana

$f(x, y)=\left[\begin{array}{cccc}f(0,0) & f(0,1) & \cdots & f(0, N-1) \\ f(1,0) & f(1,1) & \cdots & f(1, N-1) \\ \vdots & \vdots & \vdots & \vdots \\ f(M-1,0) & f(M-1,1) & \cdots & f(M-1, N-1)\end{array}\right]$ Gambar 2. Matrik Citra Digital

\section{Citra Digital}

Citra adalah suatu representasi (gambaran), kemiripan, atau imitasi dari suatu objek. Citra terbagi dua yaitu ada citra yang bersifat analog dan ada citra yang bersifat digital. Citra analog adalah citra yang bersifat kontinu seperti gambar pada monitor televisi, foto sinar-X atau hasil CT Scan. Sedangkan pada citra digital adalah citra yang dapat diolah oleh komputer.

\subsection{Citra RGB}

Citra RGB merupakan kombinasi dari elemen warna Red (merah), Green (hijau), dan Blue (biru). Format RGB ini direpresentasikan dengan menggunakan tiga layer. Setiap pixelnya merupakan kombinasi dari ketiga elemen warna tersebut, dengan tingkat warna $0-255$. Pilihan skala 256 ini didasarkan pada cara mengungkap delapan digit bilangan biner yang digunakan oleh mesin komputer.

\subsection{Citra Grayscale}

Citra grayscale berbeda dengan citra "black and white". Pada konteks komputer, citra hitam putih hanya terdiri atas dua warna saja yaitu "hitam" dan "putih" saja. Pada citra grayscale warna bervariasi antara hitam dan putih, tetapi variasi warna di antaranya sangat banyak. Terdapat tiga cara yang umum digunakan dalam mengubah citra RGB menjadi citra grayscale, yaitu Metode Lightness, Metode Average, dan Metode Luminosity.

\section{Optical Character Recognation}

OCR adalah pengenalan dari karakter teks yang tercetak atau tertulis oleh komputer. Tahap-tahap dalam proses OCR mencakup image acquisition, image preprocessing, feature extraction, dan classification.
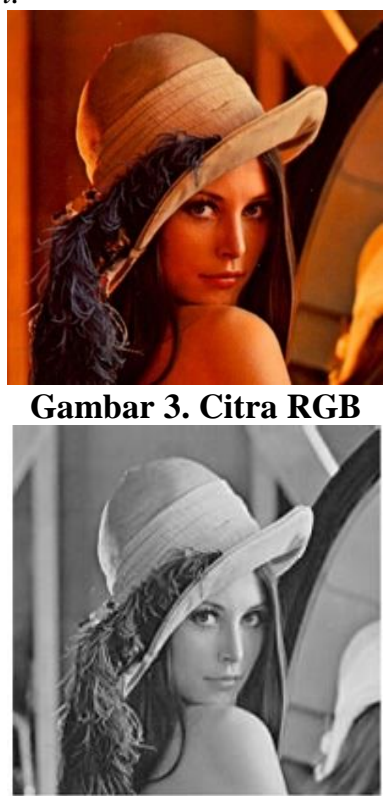

Gambar 4. Citra Grayscale 


\section{Directional Feature Extraction}

Directional Feature Extraction merupakan metode Feature Extraction dengan ciri arah dari setiap objek yang dideteksi. Pada metode ini, arah dibagi menjadi empat yaitu secara horizontal (-), vertical ( | ), left up diagonal ( $)$ ) dan right up diagonal ( 1). Untuk melakukan ekstraksi fitur berdasarkan arah dimulai dari piksel pertama yaitu piksel kiri paling atas hingga piksel paling kanan dan kemudian dilanjutkan lagi untuk nilai piksel di bawahnya. Untuk setiap piksel, dicek nilai tetangganya dari mulai piksel yang berada di atas piksel tersebut. Pengecekan dilakukan dengan searah jarum jam. Bila piksel tetangga bernilai 0 atau berwarna hitam, atur nilai sesuai ketentuan penomoran arah.

\section{Support Vector Machine}

Support Vector Machine (SVM) dikembangkan oleh Boser, Guyon, Vapnik, dan pertama kali dipresentasikan pada tahun 1992 di Annual Workshop on Computational Learning Theory. Konsep dasar SVM sebenarnya merupakan kombinasi harmonis dari teori-teori komputasi yang telah ada puluhan tahun lalu, seperti margin hyperplane, kernel yang diperkenalkan oleh Aronszajn tahun 1950, dan juga konsep-konsep pendukung lain.

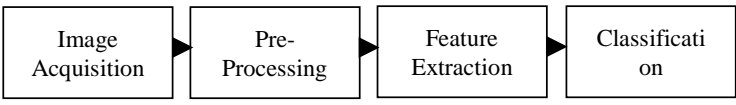

Gambar 5. Tahap-Tahap OCR

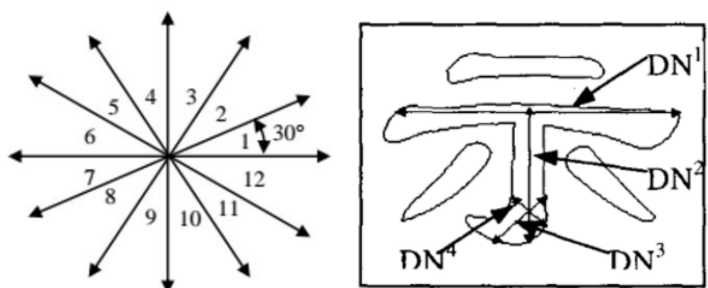

Gambar 6. Directional Feature Extraction

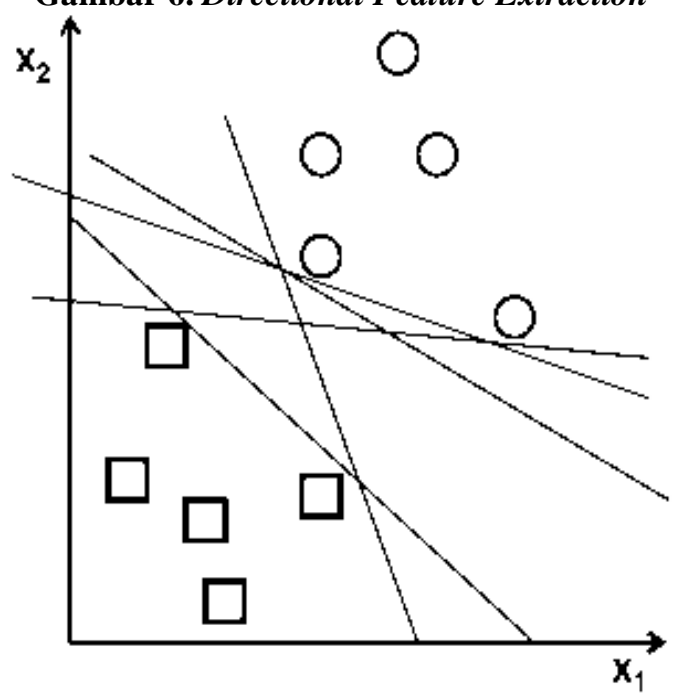

Gambar 7. Support Vector Machine

\section{Perancangan Sistem}

Sistem dirancang dan dikembangkan pada smartphone Android. Sistem yang dirancang bertujuan untuk mengenali setiap kata pada bahasa Jepang yang menggunakan huruf Hiragana dalam aplikasi penerjemah. Proses pengenalan kata bahasa Jepang diawali dengan pengambilan gambar kata Jepang. Proses pengambilan gambar dapat langsung dari capture kamera atau berupa gambar yang sudah ada pada gallery handphone. Gambar tersebut akan dideteksi menggunakan prinsip dasar Optical Character Recognation (OCR). Dengan mengunakan OCR, kata bahasa Jepang yang awalnya dalam bentuk image diubah menjadi text.

\subsection{Pre-processing}

Tahap awal dari proses pre-processing adalah grayscale. Tahap ini mengubah citra dari format RGB menjadi format grayscale (memiliki derajat keabuan). Untuk mengubah citra RGB menjadi grayscale menggunakan rumus berikut, dimana nilai pada masing-masing R, G, B tersebut dari 0-255.

Setelah grayscale, dilanjutkan dengan proses thresholding. Thresholding adalah proses mengubah citra berderajat keabuan menjadi citra biner atau hitam putih sehingga dapat diketahui daerah mana yang termasuk obyek dan background dari citra secara jelas.

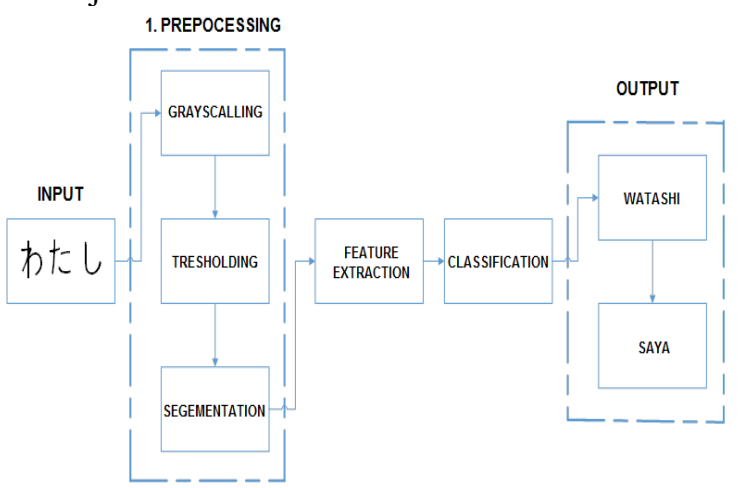

Gambar 8. Rancangan Sistem

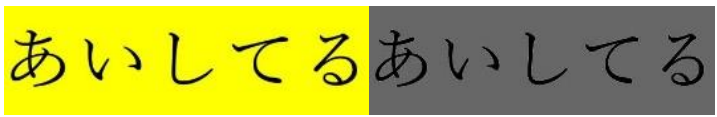

Gambar 9.(a) Sebelum Grayscale, (b) Sesudah Grayscale
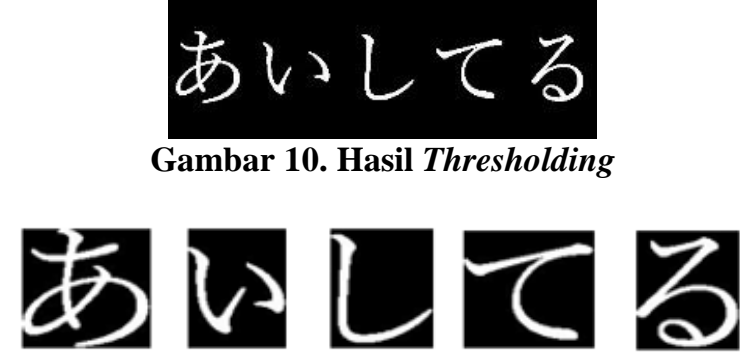

Gambar 11. Hasil Segmentasi 
Tahap selanjutnya segmentasi yang merupakan proses mempartisi citra menjadi beberapa daerah atau objek. Pada penelitian ini tahap segmentasi, dengan melakukan croping setiap silabel dari sebuah kata.

Metode yang digunakan adalah line segmentation, baik secara horizontal maupun vertical, dan Projection Block. Silabel yang didapatkan dari segmentasi akan menjadi masukan proses ekstraksi ciri.

\subsection{Ekstraksi Ciri}

Proses ekstraksi ciri merupakan pengambilan informasi-informasi penting yang terdapat pada sebuah citra. Tujuan proses ekstraksi ciri adalah mengambil beberapa informasi penting dari citra. Metode yang digunakan pada tahap ekstraksi ciri ini adalah Directional Feature Extraction. Perhitungan pada penelitian ini mengacu pada [9].

\subsection{Klasifikasi}

Tujuan dari proses pembelajaran SVM adalah untuk mendapatkan hipotesis berupa bidang pemisah terbaik (hyperplane) yang tidak hanya mengurangi empirical risk. Secara garis besar cara kerja dari Support Vector Machine adalah vektor ciri dari setiap silabel Hiragana didapat dari ekstraksi ciri DFE yang berukuran $1 \times 2500$, yang merupakan data input awal. Data training terdiri dari 104 kata yang berasal dari huruf Hiragana dalam bahasa Jepang. Setiap kata dibatasi panjangnya sebanyak maksimal 5 silabel. Data awal yang telah diolah kemudian disatukan dan dihasilkan matrik ciri, gabungan dari seluruh vektor ciri. Terdapat 104 kelas yang merupakan jumlah huruf Hiragana. Secara garis besar cara kerja dari Support Vector Machine adalah sebagai berikut:

a. Vektor ciri dari setiap silabel Hiragana didapat dari ekstraksi ciri Directional Feature Extraction yaitu matrik yang berukuran $1 \times 2500$ yang dijadikan data input awal. Data yang digunakan terbagi dua, yaitu data training dan data testing.

1) Data training terdiri dari 104 silabel yang berasal dari huruf Hiragana dalam bahasa Jepang yang berukuran $50 \times 50$ yang telah melewati proses pre-processing dan ektraksi ciri. Setiap silabel terdiri dari tiga bentuk yaitu ada bold, italic dan normal silabel, sehingga ada $3 \times 104$ silabel (312).

2) Data testing adalah citra kata bahasa Jepang yang terdiri dari huruf Hiragana Jepang. Maksimal silabel pada kata tersebut ada 5 silabel. Citra tersebut akan di pre-processing dan diekstraksi cirinya. Dan disetiap kata tersebut akan diklasifikasi oleh Support Vector Machine.

b. Data input awal 312 yang telah didapatkan ekstraksi cirinya yaitu berupa matrik $312 \times 2500$.
Setiap baris pada matriks mewakili setiap ciri pada silabel huruf Hiragana Jepang.

c. Data input awal 312 yang telah didapatkan ekstraksi cirinya yaitu berupa matrik $312 \times 2500$. Setiap baris pada matriks mewakili setiap ciri pada silabel huruf Hiragana Jepang.

\section{Pengujian Ukuran Resolusi Citra}

Pada pengujian ini, menggunakan empat ukuran resolusi citra yang umum didapatkan pada mobile android, yaitu 2,4MP, $6 M P, 13,1 M P$, dan $16 M P$. Tiap resolusi diuji dengan citra masukan yang terdiri atas 30 kata dua silabel dan tiga silabel yang sama. Masing-masing kata diambil dengan melakukan kontrol terhadap jarak pengambilan dan pencahayaan.

\section{Pengujian Waktu Respon Sistem}

Tujuan pengujian ini adalah mengetahui pengaruh kecepatan clock prosesor terhadap kecepatan waktu respon aplikasi. Aplikasi dijalankan pada beberapa jenis smartphone dengan kapasitas prosesor yang berbeda. Device dengan clock lebih besar memiliki kecepatan eksekusi data yang lebih cepat. Oleh karena itu, semakin besar clock prosesor device, semakin cepat pula waktu respon yang diperlukan aplikasi untuk menerjemahkan citra masukan.

\section{Pengujian Ketepatan Segmentasi}

Pengujian ini bertujuan untuk mengetahui ketepatan dalam proses segmentasi pada setiap kata yang diujikan. Pengujian akan dilakukan pada setiap kata berdasarkan jumlah silabel. Dari 130 data yang diuji terdapat 100 data yang hasil segmentasinya benar dan 30 data mengalami kesalahan dalam segmentasi. Pada pengujian ini dapat dilihat bahwa akurasi segmentasi tertinggi adalah $94 \%$ untuk dua silabel dan $90 \%$ untuk tiga silabel.

\section{Pengujian Deteksi Kata}

Tujuan dari pengujian ini adalah mengetahui tingkat keakuratan sistem dalam melakukan pendeteksian setiap citra masukan. Dari 130 data yang telah diuji, ada 107 data yang dideteksi benar dan 23 dideteksi salah. Pengujian ini dilakukan

Tabel 1. Hasil Pengujian Ukuran Resolusi Citra

\begin{tabular}{|c|c|c|}
\hline Resolusi & Silabel & Akurasi (\%) \\
\hline \multirow{2}{*}{$\mathbf{2 0 4 8 \times 1 1 5 2}$} & Silabel 2 & $71.43 \%$ \\
\cline { 2 - 3 } & Silabel 3 & $60 \%$ \\
\hline \multirow{2}{*}{$3264 \times \mathbf{1 8 3 6}$} & Silabel 2 & $80 \%$ \\
\cline { 2 - 3 } & Silabel 3 & $66.67 \%$ \\
\hline \multirow{2}{*}{$\mathbf{4 1 2 8 \times 3 0 9 6}$} & Silabel 2 & $85.71 \%$ \\
\cline { 2 - 3 } & Silabel 3 & $83.33 \%$ \\
\hline \multirow{2}{*}{$5312 \times \mathbf{2 9 8 8}$} & Silabel 2 & $91.42 \%$ \\
\cline { 2 - 3 } & Silabel 3 & $90 \%$ \\
\hline
\end{tabular}




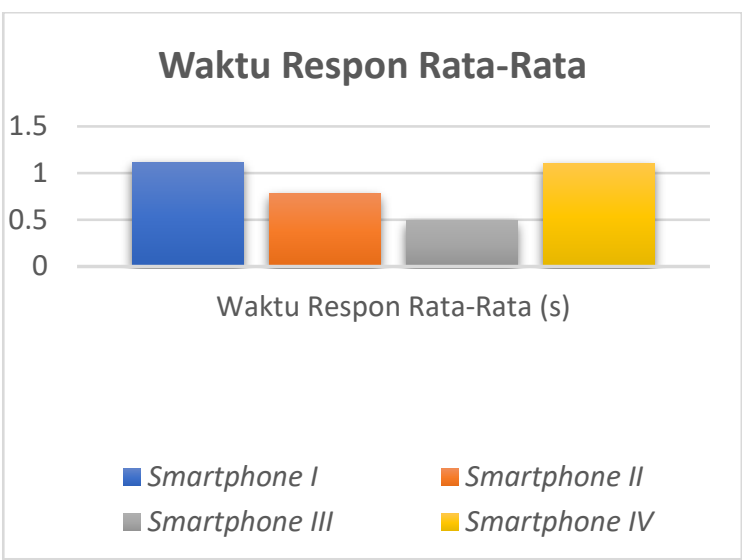

Gambar 12. Hasil Pengujian Waktu Respon Rata-Rata

Akurasi Ketepatan Segmentasi (\%)

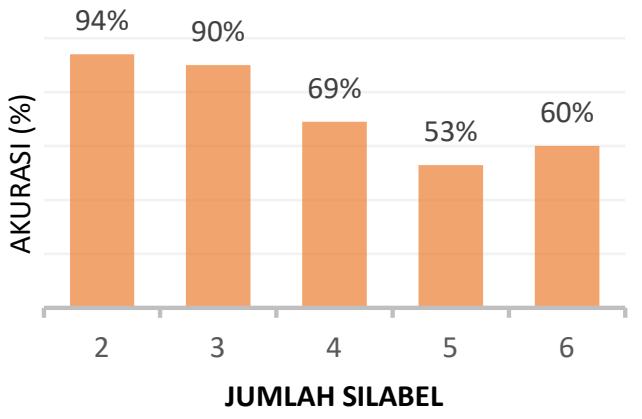

Gambar 13. Hasil Pengujian Ketepatan Segmentasi

berdasarkan banyak silabel yang terdapat pada setiap kata yang akan dideteksi. Silabel terdiri dari 2, 3, 4 dan 5. Grafik pada Gambar 14 menjelaskan nilai akurasi tertinggi pada ketepatan deteksi ini pada kata yang terdiri dari dua silabel adalah $97.14 \%$. Dari 35 jumlah kata terdapat satu kata yang terdeteksi salah.

\section{Pengujian Ketepatan Penerjemah}

Tujuan dari pengujian ini adalah mengetahui tingkat keakuratan sistem dalam melakukan penerjemahan citra masukan. Berdasarkan pengujian segmentasi, maka dipilih kata-kata bahasa Jepang yang terdiri atas dua dan tiga silabel, masing-masing 30 kata. Hasil pengujian menunjukkan nilai akurasi yang cukup tinggi, yaitu $85.71 \%$. Hal ini menunjukkan bahwa ciri yang diambil dari masingmasing silabel cukup mewakili keunikan silabel tersebut sehingga dapat dikenali oleh sistem.

\section{Pengujian Beta}

Pengujian ini dilakukan pada sisi pengguna secara objektif. Pengujian Beta merupakan pengujian berdasarkan umpan-balik dari pengguna aplikasi. Terdapat empat poin yang diujikan kepada responden, yaitu tampilan aplikasi, ketepatan

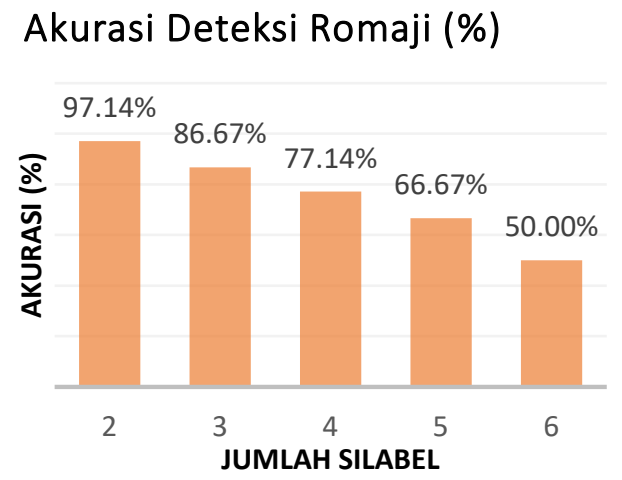

Gambar 14. Hasil Pengujian Deteksi Kata

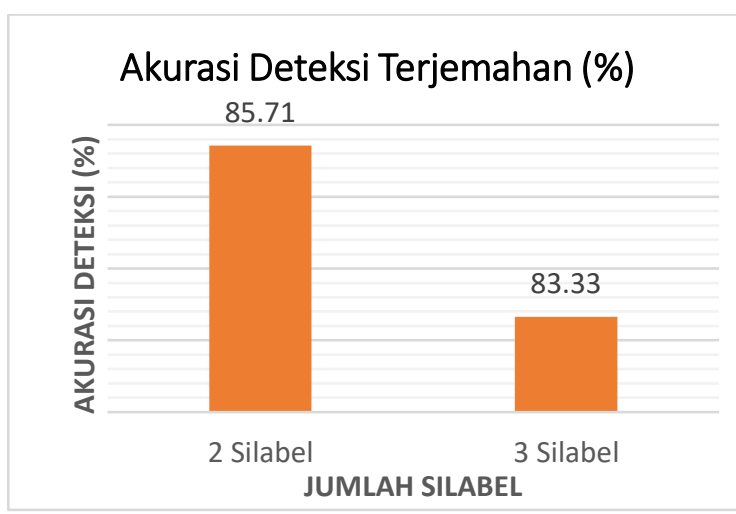

Gambar 15. Hasil Pengujian Ketepatan Penerjemahan

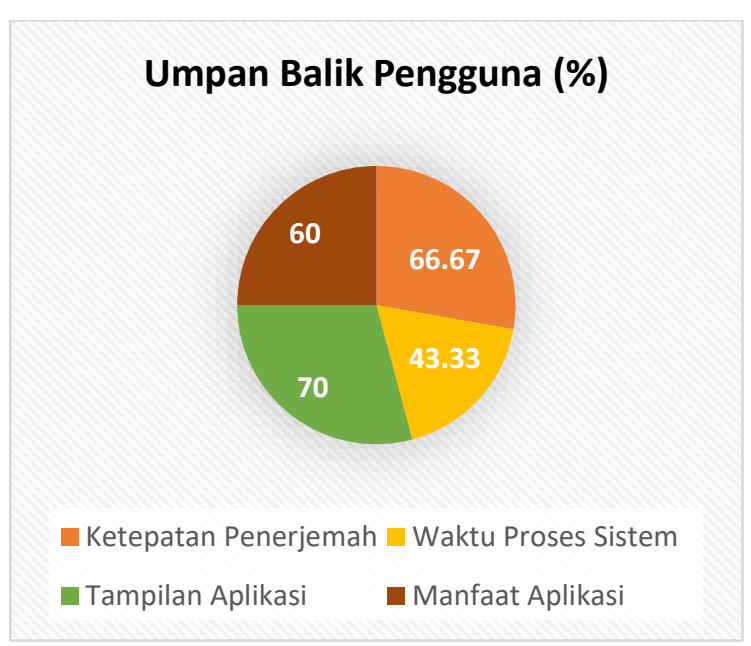

Gambar 16. Umpan Balik Pengguna

penerjemahan, lama waktu respon, serta tingkat kebermanfaatan aplikasi. Pengujian Beta dilakukan pada 30 responden yang memenuhi kriteria yang ditentukan yaitu diantaranya para pengguna smartphone android.

\section{Kesimpulan}

Penelitian ini menghasilkan kesimpulan sebagai berikut.

a. Deteksi kata pada Huruf Hiragana dalam bahasa Jepang dapat berhasil dengan menggunakan 
metode Directional Feature Extraction (DFE) pada proses ekstraksi ciri dan hasil ekstraksi ciri diklasifikasikan menggunakan metode Support Vector Machine (SVM) dengan nilai akurasi sebesar $85,71 \%$ dengan waktu respon sistem pada smartphone android dengan prosesor 1,5 $\mathrm{GHz}$ Quad Core adalah 0,778 detik.

b. Pada pengujian berdasarkan ukuran resolusi kamera akurasi tertinggi mencapai $91,42 \%$ dengan resolusi $5312 \times 2988$ piksel untuk dua silabel sedangkan untuk tiga silabel adalah 90\%. Dari pengujian dapat disimpulkan bahwa ukuran resolusi sebuah kamera, posisi objek yang akan dideteksi dan pencahayaan mempengaruhi ketepatan dalam menerjemahkan kata.

c. Perancangan dengan menggunakan ekstraksi ciri Directional Feature Extraction (DFE) serta klasifikasi dengan menggunakan metode Support Vector Machine (SVM) dapat diterapkan pada perangkat smartphone android dalam bentuk aplikasi. Berdasarkan pengujian Beta dinyatakan bahwa sebanyak $60 \%$ responden memberikan penilaian bahwa aplikasi bermanfaat untuk pengguna dalam menerjemahkan kata huruf Hiragana dalam bahasa Jepang dan $70 \%$ responden menilai tampilan aplikasi ini menarik.

\section{Daftar Pustaka}

[1] Cahyan, Pramuda Akariusta, "Segmentasi Citra Digital Dengan Menggunakan Algoritma Watershed dan Lowpass Filter Sebagai Proses Awal", Teknik Elektro Universitas Brawijaya. November 2013.

[2] Xue Gao, Lian-Wen Ji, “A New Stroke-Based Directional Feature Extraction Approach for Handwritten Chinese Character Recognition", Department of Electronics and Communication Engineering South China University of Technology, Guangzhou. 2001.

[3] Murtiwiyati dan Glenn Lauren, "Rancang
Bangun Aplikasi Pembelajaran Budaya Indonesia Untuk Anak Sekolah Dasar Berbasis Android", Fakultas Ilmu Komputer, Universitas Gunadarma. Desember 2013.

[4] Satriyo Nugroho, Anto dan Budi Witarto, Arif, "Application of Support Vector Machine in Bioinformatics". Proceeding of Indonesian Scientific Meeting in Central Japan. Desember 2003.

[5] B. Hallale, Sumedha dan D. Salunke, Geeta, "Twelve Directional Feature Extraction for Handwritten English Character Recognation". International Journal of Recent Technology and Engineering. May 2013.

[6] A.A Tayade dan R.V Mante, "Text Recognation and Translation Application for Smartphone", International Journal of Advanced Research in Computer and Communication Engineering Vol 2, Issue VI. November 2013.

[7] R.Ramanathan dan S.Ponmathavan, "Optical Character Recognation for English and Tamil Using Support Vector Machine”. Department of Electronics and Communication Engineering, India. International Conference on Advances in Computing, Control and Telecomunication Technologies. 2009.

[8] Munir, Renaldi. Pengolahan Citra Digital dengan Pendekatan Algoritmik. Bandung: Penerbit Informatika.

[9] Singh, Dayashankar, "Handwritten Character Recognation Using Twelve Directional Feature Input and Neural Network". International Journal of Computer Application. India. 2010.

[10] V. N. Vapnik, "The Nature of Support Vector Machine”. Berlin Heidelberg. 1999.

[11] N. Cristianini, "An Introduction to Support Vector Machines and Other KernelBased Learning Methods", Cambridge Press University, 2000.

[12] Chen, Jiun-Lin, "Chinese Handwritten Character Segmentation in Form Documents", National Chiao Tung University, Taiwan. 1999. 